\title{
An Analysis of the Reasons for the Rise of the Xinjiang Speed Skating Team after Being Trained and Arranged by Korean Coach Li Zaizhi
}

\author{
Yong Fu \\ Xinjiang Winter Games Management Center \\ Urumqi, China 830011
}

\author{
Juerui Wang \\ Department of Physical Education \\ Xinjiang University \\ Urumqi, China 830046
}

\begin{abstract}
In 2012, 6 members of Xinjiang speed skating team participated in the Twelfth National Winter Games, and the iceman Gekhanbay won the ninth in the men's 5000-m race that was their best result. In 2016, Xinjiang hosted the thirteenth winter games, and the Xinjiang speed skating team won the gold medal of Men's Team Chase, which is the first gold medal of winter games for the 25 years. Zhou Bin is the $3000 \mathrm{~m}$ national record holder ( 3 minutes and 46 seconds); Almas is the $5000 \mathrm{~m}$ National Record Holders (6 min 24 sec 9). In 2010, after the exchange on the Asian ice skating Association, Korean skating coach Li Zaizhi (international senior coaches) came to Xinjiang for coaching the skating team. In a short span of six years, he promoted the Xinjiang skating team and made a lot of good results, especially he led the Xinjiang skating team to get outstanding achievements in the three-person chase and participate in the world competition on behalf of China for many times, top listed in the national skating circle. With the success of 2022 Beijing and Zhangjiakou Olympic bids, we need more outstanding athletes to win gold and silver medals, so we analyze the Korean Li Zaizhi's training program in the speed skating coaching to find the reasons of Xinjiang speed skating team to win outstanding achievements, and further accumulate some experience for the construction and training of Xinjiang skating team and China skating team, and give reference for cultivation of more excellent athletes in China and learning of the advanced training concept.
\end{abstract}

Keywords — training plan; Xinjiang speed skating team; rise

\section{INTRODUCTION}

Xinjiang speed skating team appointed Korean speed skating coach Li Zaizhi and took efforts in two sessions of the National Winter Games, to finally make a breakthrough in the long distance project and win the gold medal in the thirteenth winter game. At the same time the number of pothunters has also increased significantly, especially the number of Xinjiang native athletes. The athletes trained by Coach Li Zaizhi in Korea have won three gold medals at this year's Asian Winter Games. By comparing and analyzing the results of Xinjiang speed skating team in the two sessions of winter games, the Xinjiang team has got obvious progress.

In 2012, 6 members of Xinjiang speed skating team participated in the Twelfth National Winter Games, and the iceman Gekhanbay won the ninth in the men's 5000-m race that was their best result. In 2016, Xinjiang hosted the thirteenth winter games, and the Xinjiang speed skating team won the gold medal of Men's Team Chase, which is the first gold medal of winter games for the 25 years. Zhou Bin is the $3000 \mathrm{~m}$ national record holder (3 minutes and 46 seconds); Almas is the 5000m National Record Holders (6 min $24 \mathrm{sec} 9$ ) In 2010, after the exchange on the Asian ice skating Association, Korean skating coach Li Zaizhi (international senior coaches) came to Xinjiang for coaching the skating team. In a short span of six years, he promoted the Xinjiang skating team and made a lot of good results, especially he led the Xinjiang skating team to get outstanding achievements in the three-person chase and participate in the world competition on behalf of China for many times, top listed in the national skating circle. With the success of 2022 Beijing and Zhangjiakou Olympic bids, we need more outstanding athletes to win gold and silver medals, so we analyze the Korean Li Zaizhi's training program in the speed skating coaching to find the reasons of Xinjiang speed skating team to win outstanding achievements, and further accumulate some experience for the construction and training of Xinjiang skating team and China skating team, and give reference for cultivation of more excellent athletes in China and learning of the advanced training concept.

\section{RESEARCH OBJECTS AND MethODS}

\section{A. Research Objects}

The training program of Korean, the coach Li Zaizhi is in Xinjiang Speed Skating Team, the front-line male team of Xinjiang speed skating team.

\section{B. Research Methods}

Make analysis of Coach Li Zaizhi's training program through interview, questionnaire, and data statistics.

\section{The ACHIEVEMENTS OF XINJIANG SKATING TEAM IN RECENT YEARS}

In 2016, Xinjiang hosted the 13th Winter Games and the Xinjiang skating team won the gold medal of men's team 
chase, Zhou Bin is the 3000-m national record holder ( $3 \mathrm{~min}$ $46 \mathrm{sec})$ "Table I", Almas is the 5000-m National Record
Holder (6 min $24 \sec 9)$.

TABLE I. The RESUlts List IN THE EIGHT-LAP TEAm CHASE FOR THE WORLD CUP

\begin{tabular}{|c|c|c|c|c|c|c|}
\hline Year & Game title & Place & Date & Rank & Results & Pothunter \\
\hline $2004-2005$ & The 1st station of World Cup & Norway & 2004.11 .13 & 14th & $3: 58.67$ & Chang Rui, Gao Xuefeng,Li Changyu \\
\hline $2004-2005$ & The 2nd station of World Cup & Berlin & 2004.11 .22 & 13th & $3: 56.23$ & Chang Rui, Gao Xuefeng,Li Changyu \\
\hline 2006-2007 & The 2nd station of World Cup & Berlin & 2006.11.19 & 11th & $3: 53.43$ & Jin Xin, Cheng Yue, Gao Xuefeng \\
\hline $2009-2010$ & The 2nd station of World Cup & Heerenveen & 2009.11 .15 & 13th & $3: 54.03$ & Gao Xuefeng, Jin Xin, Sun Longjiang \\
\hline $2009-2010$ & The 4th station of World Cup & Calgary & 2009.12 .06 & 11th & $3: 51.02$ & Gao Xuefeng, Jin Xin, Sun Longjiang \\
\hline $2012-2013$ & The 1st station of World Cup & Heerenveen & 2012.11 .17 & 12th & $3: 54.38$ & Li Bailin, Sun Longjiang, Xu Peng \\
\hline $2012-2013$ & The 8th station of World Cup & Elford & 2013.03 .02 & 11th & $3: 57.05$ & Li Bailin, Sun Longjiang, Xu Peng \\
\hline 2013-2014 & The 1st station of World Cup & Calgary & 2013.11 .09 & 14th & $3: 52.82$ & Sun Longjiang, Tian Guojun, Liu Yiming \\
\hline 2013-2014 & The 4th station of World Cup & Berlin & 2013.12 .07 & 14 th & $3: 58.70$ & Sun Longjiang, Tian Guojun, Liu Yiming \\
\hline 2014-2015 & The 1st station of World Cup & Obihiro & 2014.11 .15 & 10th & $3: 56.04$ & Liu Yiming, Gekhanbay, Li Bailin \\
\hline $2014-2015$ & The 3rd station of World Cup & Berlin & 2014.12 .07 & 8th & $3: 56.79$ & Liu Yiming, Gekhanbay, Li Bailin \\
\hline $2015-2016$ & The 1st station of World Cup & Calgary & 2015.11 .14 & 9th & $3: 52.92$ & Li Bailin, Tian Guojun, Sun Longjiang \\
\hline $2016-2017$ & The 1st station of World Cup & Harbin & 2016.11 .13 & 11th & $4: 00.17$ & Wu Yu, Xuan Bowen, Wang Shiwei \\
\hline $2016-2017$ & The 2nd station of World Cup & Nagano & 2016.11 .20 & 10th & $3: 55.79$ & Wu Yu, Xuan Bowen, Zhu Jiayao \\
\hline $2016-2017$ & The 3rd station of World Cup & Astana & 2016.12 .04 & 11th & $3: 57.39$ & Liu Yiming, Gekhanbay, Zhu Jiafan \\
\hline $2016-2017$ & The 4th station of World Cup & Heerenveen & 2016.12 .09 & 8th & $3: 55.66$ & Liu Yiming, Gekhanbay, Zhu Jiafan \\
\hline $2016-2017$ & Youth World Cup Final & Erfurt & 2017.02 .12 & 3rd & $3: 56.63$ & Liu Yiming, Gekhanbay, Zhu Jiafan \\
\hline $2016-2017$ & Youth World Cup championship & Finland & 2017.02 .19 & 4 th & $4: 14.98$ & Jin Yanan, Almas, Cui Zhibo \\
\hline
\end{tabular}

${ }^{\text {a. }}$ Note: since 2014, some members of Xinjiang speed skating team has participated in games on behalf of China (1)

\section{ANALYSIS ON LI ZAIZHI's TRAINING PLAN}

It is selected from Li Zaizhi's training schedule, oneweek before games and one-week on-land training schedule. The training schedule before games is made mainly based on the endurance and speed endurance. The on-land training is mainly based on endurance. For the front-line male players, coach Li's training is still mainly based on the long distance. "Table II" and "Table III"

TABLE II. ONE-WEEK SCHEDULE FOR ON-LAND TRAINING

\begin{tabular}{|l|l|l|}
\hline \multicolumn{1}{|c|}{ Date } & \multicolumn{1}{|c|}{ Time } & \multicolumn{1}{c|}{ Training Content } \\
\hline $2015.5,18$ & a.m. & (1) load-tire-pull training. (put the tire onto the bike for adding the load) \\
\hline & p.m. & (2) Balance ball practice (special technique). Stability of ankle, knee joint. \\
\hline & a.m. & (1) burst jump practice $\times 3$ groups. \\
\hline & p.m. & (1) comprehensive (waist, abdomen, back strength exercises) $\times 3$ groups. \\
\hline & a.m. & (1) Bicycle 50 km. \\
\hline & p.m. & (1) Balance ball technique. \\
\hline & a.m. & Break \\
\hline & p.m. & (1) $30 \mathrm{~m}$ run $\times 3$ groups. 50m run $\times 3$ groups. 100m run $\times 3$ groups. \\
\hline & a.m. & (1) load tire pull. \\
\hline & p.m. & (1) Balanced ball practice. \\
\hline & a.m. & (1) run for 5 laps. (2) ball athletics for 90 minutes. \\
\hline 2015.5 .5 .21 & p.m. & break \\
\hline
\end{tabular}


TABLE III. ONE-WEEK TRAINING SCHEDULE BEFORE THE GAME

\begin{tabular}{|c|c|c|}
\hline Date & $\begin{array}{c}\text { Training } \\
\text { Time }\end{array}$ & Training Content \\
\hline $10-03-2014$ & a.m. & $\begin{array}{l}\text { The preparation activities for on-land task: curve }+ \text { imitation exercises. } \\
\text { The preparation activities for going on ice: } 5 \text { laps } \times 1 \text { group. } 300 \mathrm{~m} \times 1 \text { group. } \\
\text { Task: } 5000 \mathrm{~m} \times 3 \text { groups }(35 \mathrm{sec}-37 \mathrm{sec} \text { ). (2) } 150 \mathrm{~m} \times 4 \text { group, begin skating by a big stride. (3) slow skating, jogging for } \\
20 \text { minutes. } \\
\text { The second half: } 150 \mathrm{~m} \times 4 \text { group, begin skating by a big stride (2) slow skating, jogging for } 20 \text { minutes. }\end{array}$ \\
\hline $10-03-2014$ & p.m. & $\begin{array}{l}\text { Imitation exercises for on-land task for } 2 \text { minutes } \times 4-6 \text { times, in which the technical details are required mainly. (2) do } \\
\text { waist, abdoment, back muscles exercises for a group every day. (3) Bicycle (fast for } 20 \text { minutes }+ \text { slow for } 20 \text { minutes) } \times 1 \\
\text { group. (4) Jogging for } 20 \text { minutes, and stretching exercises. }\end{array}$ \\
\hline $10-04-2014$ & a.m. & $\begin{array}{l}\text { The preparation activities for on-land activities: curve rubber band }+ \text { imitation exercises } \\
\text { The preparation activities for going on ice: } 5 \text { laps } \times 1 \text { group, } 300 \mathrm{~m} \times 1 \text { group. } \\
\text { Task: } 6 \text { laps } \times 2 \text { groups }(28 \mathrm{sec}-29 \mathrm{sec}) 5000 \mathrm{~m} \times 1 \text { group }(33 \mathrm{sec}-34 \mathrm{sec}) \\
\text { [get off the ice and take a rest : } 40 \text { minutes] } \\
\text { The second half: get on the ice } 5000 \mathrm{~m} \times 1 \text { group }(35 \mathrm{sec}-36 \mathrm{sec}) \text {. }\end{array}$ \\
\hline $10-04-2014$ & p.m. & Break time \\
\hline $10-05-2014$ & all-day & Break time \\
\hline $10-06-2014$ & a.m. & $\begin{array}{l}\text { The preparation activities for on-land task: curve rubber band }+ \text { imitation exercises } \\
\text { The preparation activities for going on ice: skating exercise } 5 \text { laps } \times 1 \text { group, } 300 \mathrm{~m} \times 1 \text { group. } \\
\text { Task: } 400 \mathrm{~m} \times 6 \text { groups }(28 \mathrm{sec}) \text { [begin after rest] } \\
\text { The second half: } 5000 \mathrm{~m} \times 3 \text { groups }(35 \mathrm{sec}-36 \mathrm{sec}),(32 \mathrm{sec}-33 \mathrm{sec}),(35 \mathrm{sec}-36 \mathrm{sec}) \text {. }\end{array}$ \\
\hline $10-06-2014$ & p.m. & $\begin{array}{l}\text { Exercise on land, jump exercise } \\
\text { (1) (jump for } 30 \text { times }+ \text { static squat for } 10 \text { seconds }+ \text { continuous jump for } 30 \text { times }) \times 2 \text { groups. } \\
\text { (2) (jump with legs separated and abdomen astringed for } 30 \text { times }+ \text { static squat for } 10 \text { seconds }+ \text { continuous jump for } 30 \\
\text { times }) \times 2 \text { group } \\
\text { (3) }(\text { single leg jump for } 15 \text { times }+ \text { Left and Right }) \times 2 \text { groups } \\
\text { (4) abdoment and back muscle } \times 2 \text { groups, for } 90 \text { seconds. }\end{array}$ \\
\hline 10-07-2014 & a.m. & $\begin{array}{l}\text { The preparation activities for on-land task: curve rubber band }+ \text { imitation exercises } \\
\text { The preparation activities for going on ice: on-ice } 5 \text { laps } \times 2 \text { groups, } 300 \mathrm{~m} \times 1 \text { group. } \\
\text { Task: } 5000 \mathrm{~m} \times 3 \text { groups }(35 \mathrm{sec}-36 \mathrm{sec}),(32 \mathrm{sec}-33 \mathrm{sec}),(35 \mathrm{sec}-36 \mathrm{sec}) \text {. } \\
\text { The second half: free skating on ice for } 20 \text { minutes }\end{array}$ \\
\hline $10-07-2014$ & p.m. & Activities on land: for $40-60$ minutes \\
\hline 10-08-2014 & a.m. & Break time \\
\hline & p.m. & (1) Free activities for 40-60 minutes. (2) stretching exercises. \\
\hline 10-09-2014 & a.m. & $\begin{array}{l}\text { The preparation activities for exercise on ice: curve rubber band }+ \text { starting exercises for race. } \\
\text { The preparation activities for going on ice: } 5 \text { laps } \times 1 \text { group, } 400 \mathrm{~m} \times 1 \text { group. } \\
\text { Task: } 5000 \mathrm{~m} \text { skate-starting race for } 2 \text { laps } \times 2 \text { groups (decided according to own level, and find the appropriate number of } \\
\text { seconds for own) } \\
\text { Free slow skating for } 20 \text { minutes, and do stretching. }\end{array}$ \\
\hline 10-09-2014 & p.m. & Free jogging for $40-60$ minutes. \\
\hline
\end{tabular}

\section{SugGeStions}

\section{A. Review of Xinjiang Speed Skating}

At the beginning of the founding of New China, the state formulated the development strategy of Snow \& Ice Games that is "northeast and northwest fly together" and organized the Xinjiang speed skating team according to the current national sports system. In the medium and late 1980s, Xinjiang Speed Skating Team won the gold medal at the National Winter Games and the National Speed Skating Competition. In the 1990s, it repeatedly won the national championship, in which the famous speed skater Liu Yanfei who came from Xinjiang, broke the Asian 1500-m men's speed skating record and won the Asian championship. With the rapid development and popularization of artificial refrigeration technology and with China's rapid economic take-off, the Northeast has built a number of artificial ice rink, so that the athletes of on-ice project have unlimited time to make training. In 1980, the Chinese Olympic delegation participated in the Winter Olympics for first time. at the time, Xinjiang speed skating team had good results, " Xinjiang speed is the national record for man's $1000 \mathrm{~m}$ $10000 \mathrm{~m}$ items except $500 \mathrm{~m}$ item meter, meters, the from
1000 meters to 10,000 meters". The members of Xinjiang speed skating team Fu Yong and Liu Yanfei and Dan Jun are jointly known as "Xinjiang Three Swordsman on Ice", and they all have won national championships for many times; Liu Yanfei always keep the winner of championship in the man's $1500 \mathrm{~m}$ project; from 1988 to 1994, he participated in the Winter Olympics for consecutive three times on behalf of China, and in 1994 he acted as the standard-bearer of Chinese delegation in the Lillehammer Winter Olympics.

In the 1990s, Xinjiang snow and ice project still depended on the nature. The construction of Xinjiang venue got behind the northeast. The performance of Xinjiang snow and ice sports declined rapidly and due to more cost in the development of ice and snow sports, the results declined seriously, and in the medium and late 1980s, the Xinjiang speed skating team is degraded as the non-key project. Since then, Xinjiang snow and ice sport enters the "winter" and it loses a chance to synchronously develop with the national ice and snow sport.

In 2012, only 6 members of Xinjiang speed skating team participated in the twelfth national winter games in Jilin Changchun, and Gekhanbay won the ninth in the men's 
5000-m race that was their best result. The gold medal won by them in this men's team chase is their first one in the winter games since 1990 after the gold generation athletes of Xinjiang skating team retired.

\section{B. The Enlightenment of the Rise of Xinjiang Speed Skating Team}

In 2009, Tong Lixin, deputy director of the Winter Games Management Center of the General Administration of Sport, newly served as deputy director general of the Sports Bureau of Xinjiang Uygur Autonomous Region, mainly in charge of ice and snow sport, and the state began to support the construction of Xinjiang ice and snow sport. By recommended by the International Ice Hockey Federation, Korean Li Zaizhi coach is employed to train the speed skating team in Xinjiang. Xinjiang speed skating team used to rely on the advantages of talent selection, and only if Xinjiang team athletes have good physical condition and persist in training, they can get achievement. Now they depend on a series of conditions, including scientific talent selection and training, perfect logistics, implementation of good policy; Xinjiang speed skating team carries out the chief coach responsibility system, and the team management and team members selection presided by chief coach, without the administrative management level intervened; all serve the team so as to have good results.

The front-line male members of Xinjiang speed skating team are mainly from Urumqi, Altay region, Barkol area, Karamay city and Changji state and other places, they are respectively Han, Kazak, Hui, Khalkhas, Uygur and other ethnic groups. They are responsible for winning the gold medal in the thirteenth winter games. Xinjiang speed skating team has started the cross-border selection of talents very early, they select some athletes with good physical conditions from the Xinjiang track and field team, roller skating team and soccer team and other projects to make training of speed skating, and after the primary election, chief coach Li Zaizhi finally decides the candidates.

\section{The Change of Xinjiang Speed Skating Team under the Guidance of Coach Li Zaizhi}

According to the results of Xinjiang speed skating team under the guidance of coach Li Zaizhi, Xinjiang speed skating team made a breakthrough in the medium and long distance, which could also be proved by his training program. He chose a correct breakthrough, which was different from previous state of Xinjiang speed skating team in outstanding short-distance achievements. The coach Li Zaizhi's level for training was recognized and he changed the previous "three-attached and one-major" training principles, more emphasized on scientific training and the physical fitness restoration after training. Coach Li Zaizhi asked his fitness trainer to serve the Xinjiang speed skating team.

We hope Li Zaizhi coach could provide a long-term teaching in Xinjiang speed skating team to lay a solid foundation for the Xinjiang speed skating team and cultivate excellent high-level speed skaters. The performance of
China's long-distance speed skating project is listed relatively behind in the world, so we hope $\mathrm{Li}$ Zaizhi coach can take the medium and long distance as a breakthrough to cultivate more excellent medium and long distance speed skaters with international level in the 2022 Beijing Olympic Winter Games. We hope to introduce foreign high-level coach through the Xinjiang speed skating team, so as to cultivate Xinjiang's native high-level coach, especially the grassroots coaches.

In 2008, China successfully held the 24th Beijing Summer Olympic Games. In the Beijing Olympic Games, China won the most gold medals, ranking first. China attaches more importance to the development of ice and snow sport. The state has developed the ice and snow sport development strategy of "north-to-south-and-west skating expansion".

Xinjiang winter project management center makes a reasonable layout of Xinjiang ice and snow project, and takes speed skating project as the breakthrough of ice project to drive the development of other ice project. Learn the successful experience in introducing Coach Li Zaizhi, spread the influence area and increase the population of Xinjiang snow and ice sport, laying a good foundation for cultivation of high-levels ice and snow talents. Do well the top design of ice and snow sport development, implement the ice and snow sport development policy, encourage us to forge ahead and make further progress. Xinjiang snow and ice sport will without fail develop into a symbol of Xinjiang winter.

\section{CONCLUSION}

According to the analysis, we find coach Li Zaizhi brings substaintial change of the Xinjiang speed skating team. He finds the breakthrough point of long-distance speed skating, which is also current weak point in Chinese speed skating, with a certain gap from the international high level. By analyzing the training program of Coach Li Zaizhi, we find his training program is more suitable for the athletes of Xinjiang speed skating team, more scientific and pertinent for solution of some problems. We look forward to Coach Li Zaizhi could bring pleasant surprise in the 2022 Beijing Olympic Winter Games.

\section{REFERENCES}

[1] Wang Fen, Study on Physical Training Theory And Practice [M] Beijing Sport University Press, September 2009

[2] Wang Fen, Study on high-level Athletic Training [M]. Beijing Spor University Press, May 2009

[3] Chen Xiaoping, Thinking on Athletic Training Practice and Development [M]. Beijing Sport University Press, March 2008

[4] Wang Juerui, et al., Discussion on the Soft Power Improvement of Xinjiang Snow And Ice Sports [J] Ice And Snow Sport, 2013.2 53-57

[5] Zhang Zhao, et al., The countermeasures for sustainable development of Xinjiang ice sports project in cultivating reserve talents [J] Ice and Snow Sport 2014.2 46-49 